\title{
Chemical profile of Festuca arundinacea extract showing allelochemical activity
}

\author{
Claudia de Bertoldi - Marinella De Leo • \\ Laura Ercoli · Alessandra Braca
}

Received: 3 May 2011/Accepted: 12 September 2011 / Published online: 25 September 2011

(C) Springer Basel AG 2011

\begin{abstract}
The allelopathic potential of fescue (Festuca arundinacea Shreb.) was investigated under field and laboratory conditions. In the field, incorporation of fescue aboveground biomass into the soil provided an effective weed control as it significantly reduced both the number and the dry weight of all weed species. The effect on weeds was species specific. The reduction of the most abundant species, Picris echioides, with respect to the number of individuals and their dry weight was 67 and $45 \%$. Fescue aboveground biomass, harvested immediately before soil incorporation, was utilized in a bioassay-oriented fractionation, aimed at identifying the compounds in the toxic extracts of the plant. While phytotoxic activity was detected for the $n$-butanol fraction, no activity was found for the aqueous one. Germination of an indicator species, lettuce (Lactuca sativa L.), was reduced by $33 \%$ at the higher extract concentration of $20 \mathrm{mg} / \mathrm{mL}$, owing to the increase of the number of abnormal seedlings. The LC/MS profile of the extract revealed the presence of two alkaloids, seven flavonol glycosides, and two flavonol aglyca. Quercetin 3-O-rutinoside, isorhamnetin 3-O-rutinoside, and kaempferol 3-O-rutinoside were reported in fescue for the first time.
\end{abstract}

C. de Bertoldi and M. De Leo contributed equally to this work.

C. de Bertoldi $\cdot$ L. Ercoli $(\bowtie)$

Scuola Superiore Sant'Anna, Piazza Martiri della Libertà 33, 56127 Pisa, Italy

e-mail: ercoli@sssup.it

M. De Leo - A. Braca

Dipartimento di Scienze Farmaceutiche, Università di Pisa,

Via Bonanno 33, 56126 Pisa, Italy
Keywords Festuca arundinacea . HPLC-PDA/ESI-MS · Flavonol glycosides . Allelochemicals $\cdot$ Pyrrolizidine alkaloids

\section{Introduction}

Allelopathy refers to any process involving secondary metabolites produced by plants, microorganisms, viruses, and fungi that influence growth and development of agricultural and biological systems, including positive and negative effects (Rice 1984). Allelochemicals from plants are released into the environment by exudation from roots, leaching from stems and leaves or decomposition of plant material (Rice 1984; Lovett and Ryuntyu 1992; Rizvi and Rizvi 1992). During the microbial decomposition and enzymatic degradation of such plant material, a wide range of chemicals are released into the soil, where many of them exhibit important biological activities, such as inhibition of seed germination, plant growth, and yield reduction of many crops (McCalla 1971).

Festuca arundinacea Shreb., commonly known as tall fescue, is a cool-season perennial C3 species native in Europe. It is an important forage grass which is also used as an ornamental species in golf course fairways, athletic fields, and private and public lawns throughout the temperate regions of North and South America and Europe.

Tall fescue was found to possess allelopathic activity. Gilmore (1977) reported that fescue leachates significantly reduced the growth of sweet gum (Liquidambar styraciflua L.) seedlings. Water extracts of tall fescue reduced germination and seedling growth of alfalfa, Italian ryegrass and clover (Smith and Martin 1994; Springer 1996). In laboratory bioassays Bertin et al. (2003) also demonstrated the allelopathic effect of fescue root exudates and extracts 
from shoot and root tissues. As inhibitory compounds present in the anionic fraction of aqueous leachates of tall fescue leaves and roots, Peters and Lun (1985) found a number of organic acids including lactic, succinic, malic, citric, shikimic, glyceric, fumaric, quinic, and some unknowns. The presence of phenolic acids was not mentioned. Conversely, Buta and Spaulding (1989), reported phenolic inhibitors to be present in leachates from tall fescue, and their level was high enough to cause growth inhibition. The major growth inhibitor, however, was found to be abscisic acid (ABA). Finally, Sanchez-Moreiras et al. (2004) stated that allelochemicals of $F$. arundinacea extracts were not identified.

In this context, the aim of our work was to study the allelopathic potential of fescue ( $F$. arundinacea Shreb.), by carrying out field and laboratory experiments. The weed suppressive ability of fescue was determined under field conditions, following soil incorporation of the crop. Aboveground plant biomass, harvested immediately before soil incorporation, was utilized in a bioassay-oriented fractionation, aimed at identifying phytotoxic compounds in plant tissues by High Performance Liquid Chromatography coupled with Photo Diode Array and Electrospray Ionization Tandem Mass Spectrometry detectors (HPLCPDA/ESI-MS/MS).

\section{Materials and methods}

Field experiments

Festuca arundinacea Schreb. var. Villegeoise was grown in open fields at the Experimental Research Station of the Department of Agronomy and Agroecosystem Management, University of Pisa, in S. Piero a Grado, near Pisa, Italy $\left(43^{\circ} 67^{\prime} \mathrm{N}, 10^{\circ} 30^{\prime} \mathrm{E}, 5 \mathrm{~m}\right.$ above sea level) from October 2006 to March 2007. The climate is typically Mediterranean, the mean annual rainfall is $970 \mathrm{~mm}$ (drywarm period in summer and cool-rainy period in autumn), and mean monthly temperatures and rainfall range from $7^{\circ} \mathrm{C}$ and $78 \mathrm{~mm}$ in January to $22^{\circ} \mathrm{C}$ and $24 \mathrm{~mm}$ in July, respectively. Physical and chemical properties of the soil were: $57.8 \%$ sand; $22.4 \%$ silt; $19.8 \%$ clay; $\mathrm{pH} 6.3 ; 1.4 \%$ organic matter.

A randomized experimental design with three replications was adopted; the size of blocks was $5 \times 5 \mathrm{~m}$. The treatments consisted of incorporation of fescue aboveground biomass into the soil compared to bare soil (control). On December 6th the field was plowed, disked and smoothed with a harrow, and $F$. arundinacea was drilled at $40 \mathrm{~kg}$ seeds $/ \mathrm{ha}$. The control plot was prepared with the same tillage method as that used for the fescue crop. Production of aboveground biomass of fescue was determined, immediately before crop incorporation into the soil, by harvesting $1 \mathrm{~m}^{2}$ area from each block. Fresh biomass was incorporated into the soil on May 21st with a disk harrow at $10-15 \mathrm{~cm}$ depth when fescue plants were at the stage of anthesis (stage 60 of the scale of Zadoks et al. 1974). The block with bare soil was also plowed. Six weeks after soil incorporation, the individual number and biomass (dry weight) of all weed species were determined by harvesting all plants in a $1 \mathrm{~m}^{2}$ area.

\section{Reagents}

HPLC grade acetonitrile, methanol, and acetic acid were purchased from J.T. Baker (Baker Mallinckrodt, Phillipsburg, NJ, USA). HPLC grade water $(18 \mathrm{~m} \Omega)$ was prepared by a Milli $\Omega^{50}$ purification system (Millipore Corp., Bedford, MA, USA). Standards of isorhamnetin 3-O-glucoside, quercetin 3-O-rutinoside, isorhamnetin 3-O-rutinoside, and kaempferol 3-O-rutinoside were previously isolated and fully characterized in our laboratory from plants belonging to Moraceae and Rosaceae families.

\section{Extraction and fractionation}

Immediately before the incorporation into the soil, the aerial parts of the fescue plants were harvested, oven dried at $40^{\circ} \mathrm{C}$, chopped into small pieces, and $100 \mathrm{~g}$ dry weight was extracted with methanol by exhaustive maceration $(5 \times 100 \mathrm{~mL})$. The solvent was removed in vacuo at $40^{\circ} \mathrm{C}$ to yield $17.1 \mathrm{~g}$ as a residue, which was successively partitioned between $n$-hexane and water. The water portion was further partitioned between $n$-butanol and water to obtain 4.1 and $6.5 \mathrm{~g}$ of dried extract, respectively. The dried $n$-butanol extract was further purified by Solid Phase Extraction (SPE) RP-18 eluting with methanol:water 9:1 solution and, after filtration, analyzed by LC-PDA/ESIMS $(1.0 \mathrm{mg} / \mathrm{mL}$ methanol solution).

\section{Bioassays}

The amounts of samples used for the bioassays were calculated on the basis of the dry weight of the extracted material. The extracts (total extract, $n$-butanol, and water fractions) were dissolved in distilled water to obtain six different concentrations $(3.3,4.0,5.0,6.7,10.0$, and $20.0 \mathrm{mg} / \mathrm{mL}$ ). The osmotic potential of each test solution was determined using a cryoscopic osmometer (OSMOMAT 030, Gonotec). The osmotic potential of the solution with the highest concentration solution was $98 \mathrm{mOsmol} / \mathrm{kg}$; the osmotic potential of further dilutions was below $47 \mathrm{mOsmol} / \mathrm{kg}$. Following Elakovich and Wooten (1991) growth of lettuce seedlings is not affected by aqueous extracts with osmotic potential lower than 
$70 \mathrm{mOsmol} / \mathrm{kg}$. Thus, the osmotic potential of the extracted solutions may be considered non-influential on germination.

Following Belz and Hurle (2004), the pH of each test solution was also determined to distinguish the effect of allelopathy from that of acidification. Values of extract concentrations ranged from 5.1 to 5.7 in the total extract from 4.7 to 5.1 in $n$-butanol and from 5.7 to 6.0 in water fractions, respectively. According to Elakovich and Wooten (1991) and Macias et al. (2000), pH values from 4 to 6 did not affect lettuce germination. Moreover, in a preliminary germination test with distilled water and a $\mathrm{pH}$ adjusted to 4.0, germination of lettuce seeds was not significantly different from the control with distilled water.

The seedling growth assays were done using lettuce seeds (Lactuca sativa L.) with all fractions. Although lettuce is not the species co-occurring with the donor plant fescue, it was selected in this research since it is widely used as a standard target species because of its high sensitivity and fast germination (Macias et al. 2000).

The assays were performed in 20-cm Petri dishes using 100 seeds and $6 \mathrm{~mL}$ of test solution with three replicates. Dishes were placed in a growth chamber at $20^{\circ} \mathrm{C}$, after $48 \mathrm{~h}$ of pre-chilling at $4^{\circ} \mathrm{C}$ and were arranged in a randomized complete block design. Dishes were checked regularly, and deionized water was added as needed. For 7 days, germinated seeds were counted at 24-h intervals. A seed was regarded germinated when the radicle had protruded at least $1 \mathrm{~mm}$. At 7 days after sowing, root and hypocotyl lengths of the germinated seeds were measured on all seedlings in each Petri dish, and the number of abnormal and dead seeds was also recorded, following ISTA (2005).

Mean germination time (MGT) was calculated, following Oyun (2006), as:

MGT $=\sum(N \times d) / \sum N$

where $N$ is the number of seeds germinated on day $d$, and $d$ is the number of days since the start of the germination test.

\section{Statistics}

All data were tested for homogeneity of variance using a Bartlett test (Snedecor and Cochran 1989). One-way ANOVA was performed on $\log _{10}$ transformed data when necessary; re-transformed mean values are presented in the result section. Duncan's multiple range test was used to test for significant differences between treatment groups when the ANOVA $F$ test indicated a significant effect of the treatment (Steel and Torrie 1980).

\section{LC-PDA/ESI-MS analyses}

The LC-MS/MS analyses were performed using a Surveyor LC pump, a Surveyor Autosampler, coupled with an LCQ Advantage ion trap mass spectrometer (Thermo Finnigan, San Jose, CA, USA) and equipped with Xcalibur 3.1 software. LC separation was performed on a $4.6 \times$ 150 mm, Sinergi 4 u Fusion RP-80A column (Phenomenex Corp., Torrance, CA). The eluent was a mixture of $0.1 \%$ acetic acid in acetonitrile [solvent $\mathrm{A}$ ] and $0.1 \%$ acetic acid in water [solvent B]. The solvent gradient was as follows: 0-35 min, 5-40\% (A). The elution was performed at a flow rate of $0.8 \mathrm{~mL} / \mathrm{min}$ with a splitting system of $2: 8$ to the MS detector $(200 \mu \mathrm{L})$ and the PDA detector $(800 \mu \mathrm{L})$, respectively. The total running time was $35 \mathrm{~min}$. The volume of the injection was $20 \mu \mathrm{L}$. The analysis was performed with an ESI interface in the positive ionization mode. Ionization conditions were optimized, and the following parameters were used: capillary temperature, $280^{\circ} \mathrm{C}$; capillary voltage, $3 \mathrm{~V}$; tube lens offset, $55 \mathrm{~V}$; sheath gas flow rate, 60 ; auxiliary gas flow rate 6.0; source voltage, $4.5 \mathrm{kV}$. $\mathrm{N}_{2}$ was used as sheath and auxiliary gas. Mass spectra were recorded in a mass range of $\mathrm{m} / \mathrm{z}$ 150-1500. PDA data were recorded with $220-480 \mathrm{~nm}$.

\section{Results}

\section{Field experiments}

At soil incorporation, the dry weight of $F$. arundinacea was $189.1 \mathrm{~g} \mathrm{~m}^{-2}$, which is an expected value for this species cultivated as cover crop in our environment. The incorporation of fescue biomass into soil provided an effective weed control in field conditions, as it significantly reduced both the number and the dry weight of all weed species. The reduction was over $50 \%$ for both characters (Table 1). Fescue showed a species-specific impact on weeds, as it did not affect Amaranthus sp. and Veronica sp., but completely inhibited Anagallis sp. and Sinapis sp., and reduced Picris echioides, Solanum nigrum, and Veronica sp. The reduction for the most abundant species $P$. echioides was 67 and $45 \%$, for the number of individuals and for their dry weight, respectively. The toxic effect of $F$. arundinacea has already been well documented in literature (Smith and Martin 1994; Springer 1996; Bertin et al. 2003).

\section{Bioassays}

The plant biomass was initially extracted with methanol and tested for phytotoxic activity. The extract was active and partitioned between $n$-butanol and water. The $n$-butanol fraction was active, whereas the water fraction was 
Table 1 Number and weight of weed species grown in bare soil and in soil after fescue incorporation

Within each row and weed characteristic, numbers followed by the same letter are not significantly different at $P \leq 0.05$

\begin{tabular}{|c|c|c|c|c|}
\hline \multirow[t]{2}{*}{ Weed species } & \multicolumn{2}{|c|}{ Plants $\left(\mathrm{n} \mathrm{m}^{-2}\right)$} & \multicolumn{2}{|c|}{ Dry weight $\left(\mathrm{g} \mathrm{m}^{-2}\right)$} \\
\hline & Bare soil & $\begin{array}{l}\text { Fescue } \\
\text { incorporation }\end{array}$ & Bare soil & $\begin{array}{l}\text { Fescue } \\
\text { incorporation }\end{array}$ \\
\hline Amarantus sp. & $1.3 \mathrm{a}$ & $1.3 \mathrm{a}$ & $3.2 \mathrm{a}$ & $2.3 \mathrm{~b}$ \\
\hline Anagallis sp. & $2.7 \mathrm{a}$ & $0.0 \mathrm{~b}$ & $0.4 \mathrm{a}$ & $0.0 \mathrm{~b}$ \\
\hline Picris echioides & $44.0 \mathrm{a}$ & $14.7 \mathrm{~b}$ & $59.3 \mathrm{a}$ & $32.7 \mathrm{~b}$ \\
\hline Sinapis sp. & $2.7 \mathrm{a}$ & $0.0 \mathrm{~b}$ & $3.9 \mathrm{a}$ & $0.0 \mathrm{~b}$ \\
\hline Solanum nigrum & $10.7 \mathrm{a}$ & $1.3 \mathrm{~b}$ & $9.5 \mathrm{a}$ & $0.5 \mathrm{~b}$ \\
\hline Veronica sp. & $16.7 \mathrm{a}$ & $16.0 \mathrm{a}$ & $4.9 \mathrm{a}$ & $0.5 \mathrm{~b}$ \\
\hline Total & $78.1 \mathrm{a}$ & $33.3 \mathrm{~b}$ & $81.2 \mathrm{a}$ & $36.0 \mathrm{~b}$ \\
\hline
\end{tabular}

completely inactive. Since methanol and $n$-butanol extracts caused similar effects on lettuce seeds on the whole range of concentrations examined, only the results obtained with the $n$-butanol extract are reported here.

The $n$-butanol extract of $F$. arundinacea significantly affected the germination rate of lettuce, as well as the development of seedlings (Fig. 1). The magnitude of the effect was dependent on the concentration of the extract. Germination was reduced by $33 \%$ at extract concentrations higher than $10 \mathrm{mg} / \mathrm{mL}$, while it was not affected at concentrations of $6.7 \mathrm{mg} / \mathrm{mL}$ and below. When compared to the control, the mean germination time increased up to a concentration of $10 \mathrm{mg} / \mathrm{mL}$ and decreased subsequently. The reduction of germination mainly depended on the increasing number of abnormal seedlings, as the number of ungerminated seeds was little affected. The $n$-butanol extract showed inhibitory activity on hypocotyl elongation of germinated seeds only at the highest concentrations, while inhibited root elongation was observed at all concentrations, with progressively increasing effects at elevated concentrations. An extract concentration of $20 \mathrm{mg} / \mathrm{mL}$ resulted in a $53 \%$ reduction in root length while the hypocotyl length was reduced by $37 \%$ as compared to the control.
Fig. 1 Results of bioassays using an $n$-butanol extract of $F$. arundinacea
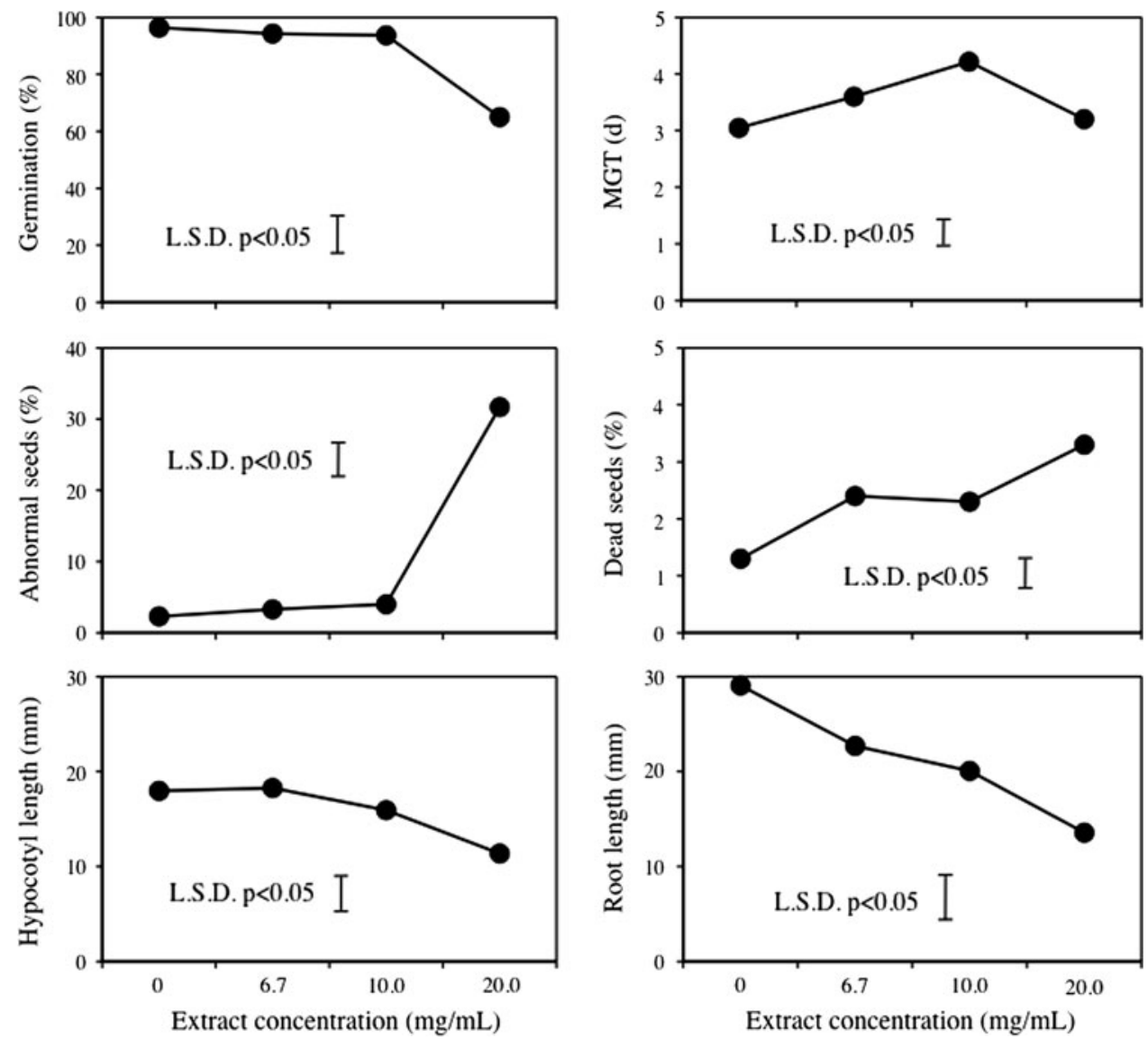
Identification of allelochemicals

As a consequence of the results obtained in the bioassays, the $n$-butanol extract of $F$. arundinacea biomass, showing highest phytotoxic activity, was investigated by means of HPLC-PDA/ESI-MS/MS analysis, to study its profile of secondary metabolites. The resulting chromatogram is shown in Fig. 2a. Extracted ion chromatograms revealed the presence of different peaks, corresponding to alkaloids (peaks $\mathbf{1}$ and 2; Fig. 2b, c), flavonol glycosides (peaks 3-9; Fig. 2d-i), and flavonol aglyca (peaks 10 and 11; Fig. 2j, $k)$. The identification of compounds was performed on the basis of their UV spectra, retention times, molecular weights, and fragmentation pattern of precursor ions deduced from ESI-MS/MS spectra. The structures of identified compounds are reported in Fig. 3. The full mass spectrum of peak 1 showed a protonated molecule $[\mathrm{M}+\mathrm{H}]^{+}$at $m / z 434$, suggesting the presence of nitrogen. The collision-induced fragmentation yielded ions at $\mathrm{m} / \mathrm{z} 288$ and $\mathrm{m} / \mathrm{z} 142$, generated by the loss of two neutral fragments of $146 \mathrm{U}$ corresponding to a rhamnose and a p-coumaroyl residue (Fig. 4a). These data, together with $\lambda_{\max }$ at $305 \mathrm{~nm}$ detected by HPLC/PDA, suggested peak $\mathbf{1}$ to be the pyrrolizidine alkaloid E/Z-thesinine- $O-4^{\prime}$ $\alpha$-rhamnoside (Koulman et al. 2008). The second pyrrolizidine alkaloid (peak 2) was identified to be $E / Z$-thesinine, as deduced by the ion $[\mathrm{M}+\mathrm{H}]^{+}$at $\mathrm{m} / \mathrm{z}, 288$ and the parent ion at $m / z, 142$ (Fig. $4 b$ ). The $\lambda_{\max }$ at $305 \mathrm{~nm}$ confirmed that the chromophore was a $p$-coumaroyl group corresponding to a neutral loss of $146 \mathrm{U}$ from the molecular ion, leaving a fragment at $\mathrm{m} / \mathrm{z} 142$, in both compounds $\mathbf{1}$ and 2, as previously reported (Koulman et al. 2008). The presence of pyrrolizidine alkaloids in fescue, independent of the presence of endophytic fungi, was reported by Koulman et al. (2008).

The UV spectra of peaks $\mathbf{3}, \mathbf{5}$, and $\mathbf{7}$ were typical for flavonoid glycosides as indicated by absorbances at 255-265 and 330-355 nm detected by HPLC PDA (Wollenweber 1982). Comparison with data reported in the literature about flavonoids isolated in fescue suggested peak 3 to be quercetin-3- $O$-xylosylglucoside or quercetin3-O-arabinosylglucoside and peak 7 to be isorhamnetin
Fig. 2 HPLC/ESI-MS chromatogram of an $n$-butanol extract of $F$. arundinacea (a) and extracted ion chromatograms of all compounds detected (b-k)

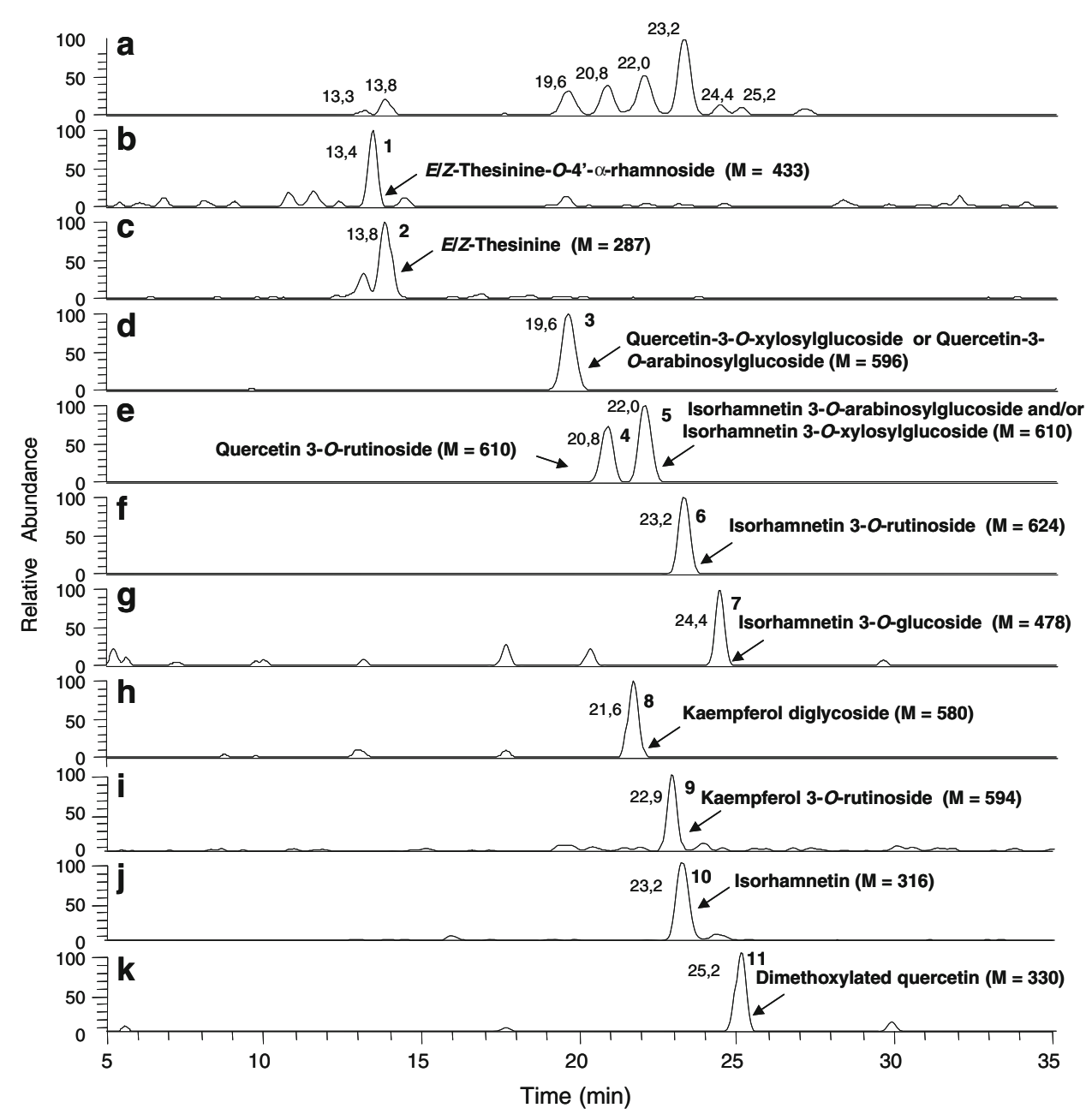


Fig. 3 Chemical structures of alkaloids (1 and 2) and flavonoids (3-10) from $F$. arundinacea. Glc glucose, $X y l$ xylose, Ara arabinose, Rha rhamnose

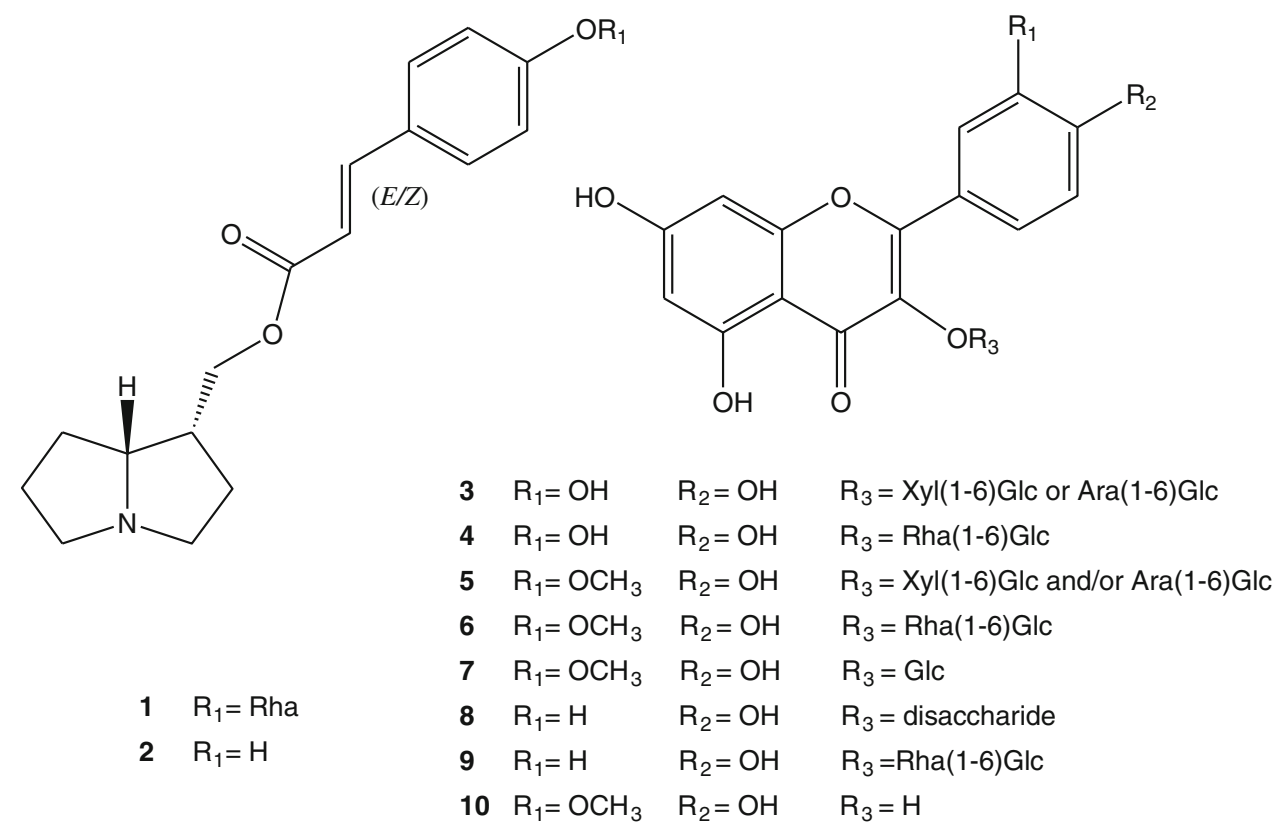

spectrum of peak 5 showed $[\mathrm{M}+\mathrm{Na}]^{+}$at $\mathrm{m} / z$ 633, corresponding to a molecular weight of $610 \mathrm{U}$. The MS/MS spectrum of the precursor ion (Fig. 5b) displayed a diagnostic fragment at $\mathrm{m} / \mathrm{z} 501$ generated by the loss of a pentose unit $\left([\mathrm{M}+\mathrm{Na}-132]^{+}\right)$, attributable to a xylose or arabinose residue, and a base peak at $\mathrm{m} / \mathrm{z} 317$ corresponding to a sodium-cationized diglycoside (pentose plus hexose), generated by the loss of $316 \mathrm{U}$, corresponding to the aglycon isorhamnetin.

The molecular weight of compound 7 was $478 \mathrm{U}$, as deduced by a sodium-cationized species $[\mathrm{M}+\mathrm{Na}]^{+}$at $\mathrm{m} / \mathrm{z}$ 501 , suggesting the identification of this compound as isorhamnetin 3-O-glucoside, previously detected in fescue. Comparison of its HPLC retention time, ESI-MS
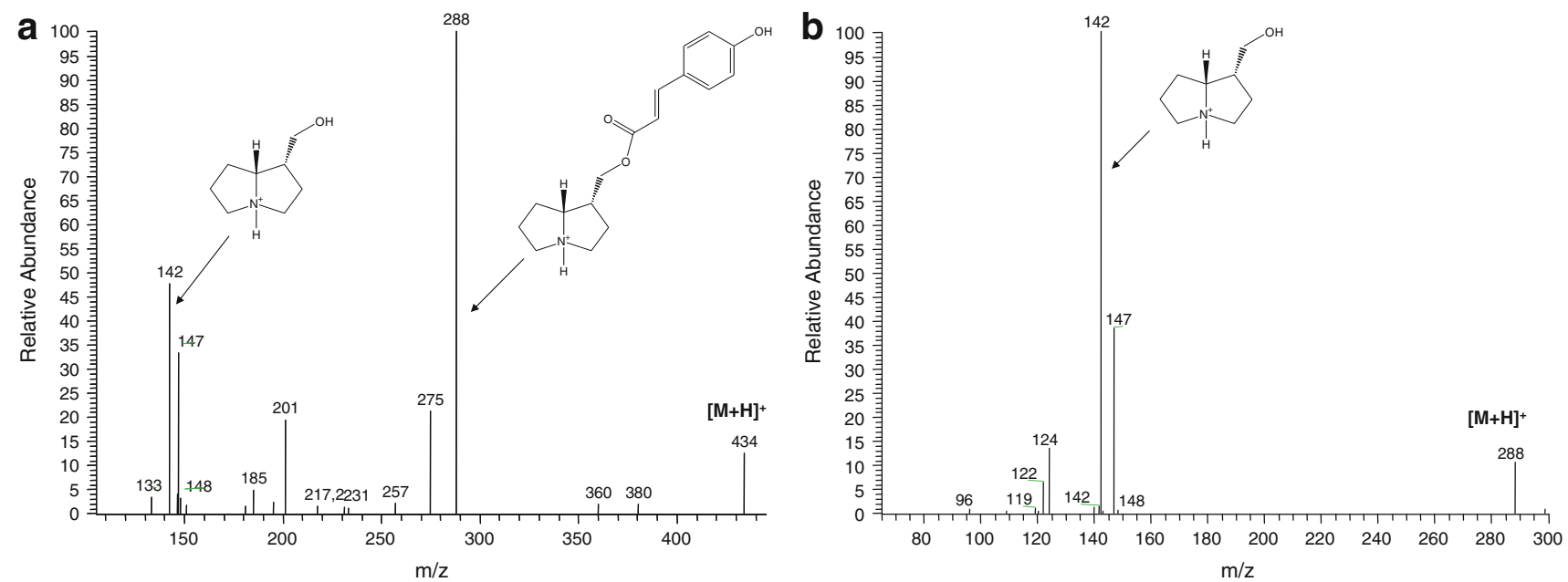

Fig. 4 ESI-MS/MS spectra of protonated molecules $[\mathrm{M}+\mathrm{H}]^{+}$of the pyrrolizidine alkaloids $E / Z$-thesinine- $O-4^{\prime}-\alpha$-rhamnoside $(\mathbf{a})$ and $E / Z$ thesinine (b) 

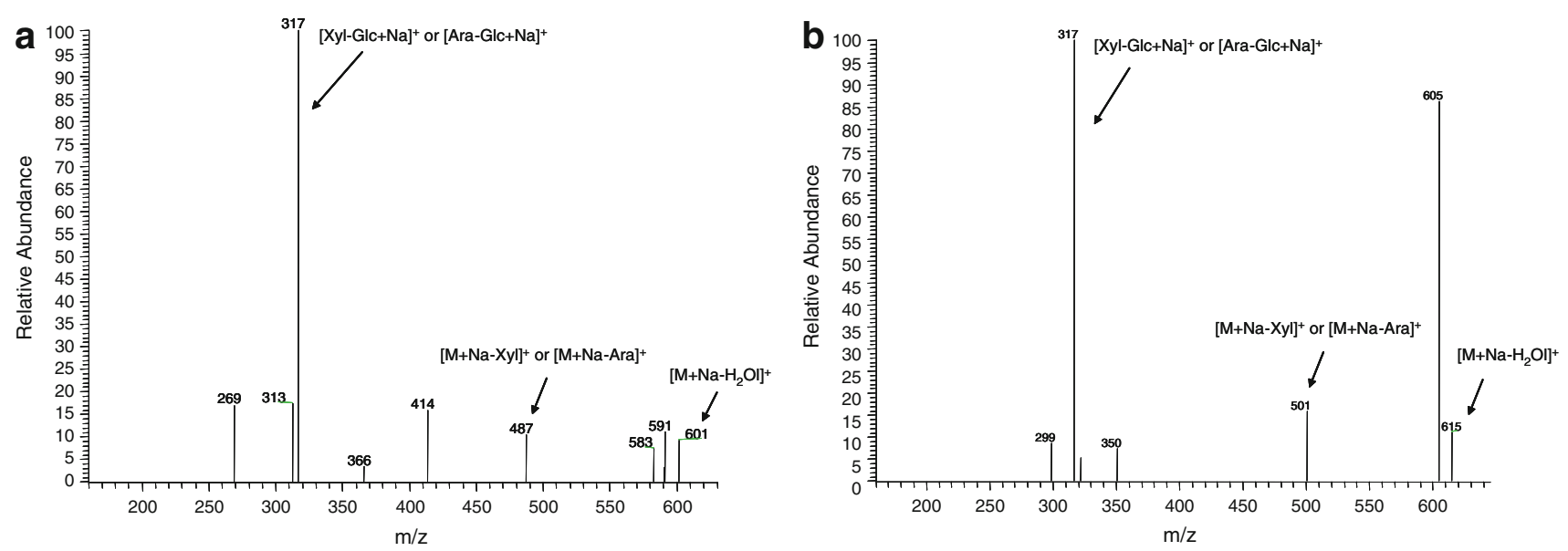

Fig. 5 ESI-MS/MS spectra of ions $[\mathrm{M}+\mathrm{Na}]^{+}$of flavonol glycosides $\mathbf{3}$ (a) and $\mathbf{5}$ (b)

spectrometric data, and photodiode array PDA/UV-vis with an authentic reference compound, confirmed our hypothesis. These evidences were in accordance with data reported in the literature for flavonol glycosides identified in F. arundinacea (Wong 1980).

The HPLC/MS profile of the $n$-butanol extract of $F$. arundinacea revealed the presence of four more flavonol diglycosides, having quercetin and kaempferol as aglyca that had never been reported before in fescue. These compounds displayed molecular weights of $610 \mathrm{U}$ (peak 4), $624 \mathrm{U}$ (peak 6), $580 \mathrm{U}$ (peak 8), and $594 \mathrm{U}$ (peak 9), respectively. A tandem mass spectrometry study was carried out to attempt structure elucidations, on the basis of collision-induced fragmentation observed for flavonoids (Cuyckens and Claeys 2004). Collision-induced fragmentation of the precursor ion $[\mathrm{M}+\mathrm{Na}]^{+}$at $m / z 633$ (peak 4; Fig. 6a) produced a base peak at $m / z$ 487, due to the loss of a deoxyhexose unit $\left([\mathrm{M}+\mathrm{Na}-146]^{+}\right)$and a diagnostic fragment at $m / z$ 331, a sodium-cationized diglycoside (deoxyhexose plus hexose) generated by the loss of $302 \mathrm{U}$, revealing the aglycon to be quercetin. Similarly, fragmentation of the precursor ion $[\mathrm{M}+\mathrm{Na}]^{+}$at $m / z 647$ (peak 6; Fig. 6b) generated diagnostic ions at $m / z 501([\mathrm{M}+\mathrm{Na}-$ $146]^{+}$), corresponding to the loss of a rhamnose unit and at $m / z 331\left([\mathrm{M}+\mathrm{Na}-316]^{+}\right)$, due to the loss of the aglycon isorhamnetin. Comparison with pure compounds, isolated in our laboratory from plant sources, showed compound 4 to be quercetin 3-O-rutinoside and compound 6 to be isorhamnetin 3-O-rutinoside, respectively. MS/MS spectra of the peaks 8 and 9 revealed $[\mathrm{M}+\mathrm{Na}]^{+}$ions at $\mathrm{m} / \mathrm{z} 603$ (Fig. 6c) and 617 (Fig. 6d), showing product ions at $\mathrm{m} / \mathrm{z} 471$ in both compounds, generated by the loss of a pentose unit $\left([\mathrm{M}+\mathrm{Na}-132]^{+}\right)$for 8 and a deoxyhexose $\left([\mathrm{M}+\mathrm{Na}-146]^{+}\right)$for $\mathbf{9}$, respectively. Detection of ions at $\mathrm{m} / \mathrm{z} 317$ and 331, corresponding to sodium-cationized disaccharides, suggested that both compounds carried a sugar chain linked to a kaempferol aglycon (286 U). The difference between the two flavonol glycosides laid in the sugar chains: the disaccharide of $\mathbf{8}$ was comprised of one pentose and one hexose residue, while in the sugar chain of 9 a hexose unit was linked to a deoxyhexose. Compound 9 was identified as kaempferol 3-O-rutinoside by comparison of its retention time and fragmentation pattern with an authentic reference compound. The exact structure of compound $\mathbf{8}$ remained unidentified since no pure compound was available for comparison.

Finally, some aglyca were detected in the $n$-butanol extract. Peak 10 showed the protonated molecule at $\mathrm{m} / \mathrm{z}, 317$ and diagnostic signals at $\mathrm{m} / \mathrm{z}, 302\left(\left[\mathrm{M}+\mathrm{H}-\mathrm{CH}_{3}\right]^{+}\right)$, $289\left([\mathrm{M}+\mathrm{H}-\mathrm{CO}]^{+}\right), 285\left(\left[\mathrm{M}+\mathrm{H}-\mathrm{H}_{2} \mathrm{O}\right]^{+}\right), 261([\mathrm{M}+\mathrm{H}-$ $\left.2 \mathrm{CO}^{+}\right), 165$, and 153 , the last two peaks corresponding to a ${ }^{0,2} \mathrm{~A}+$ and ${ }^{1,3} \mathrm{~A}+$ fragment, respectively (Fig. 7a), in accordance with data reported for isorhamnetin (Ma et al. 1997). Analysis of the MS/MS spectrum of the ion at $\mathrm{m} / \mathrm{z} 331$ (peak 11; Fig. 7b) revealed product ions at $m / z, 316$ and 301, generated by the loss of two methyl-groups, suggesting the presence of a dimethoxylated quercetin; unfortunately, it was impossible to determine the positions of the methoxy groups from the fragmentation pattern. Thus, compound $\mathbf{1 1}$ remained unidentified.

\section{Discussion}

Results of field experiments demonstrated that soil incorporation of $F$. arundinacea provided a satisfactory weed control, inhibiting seed germination and reducing growth of germinated seedlings. This effect is likely to be due to the release of allelochemicals during the decomposition of biomass following incorporation into the soil. Fractionation of plant extracts into $n$-butanol and water fractions was followed by bioassays. Growth inhibition was found only 

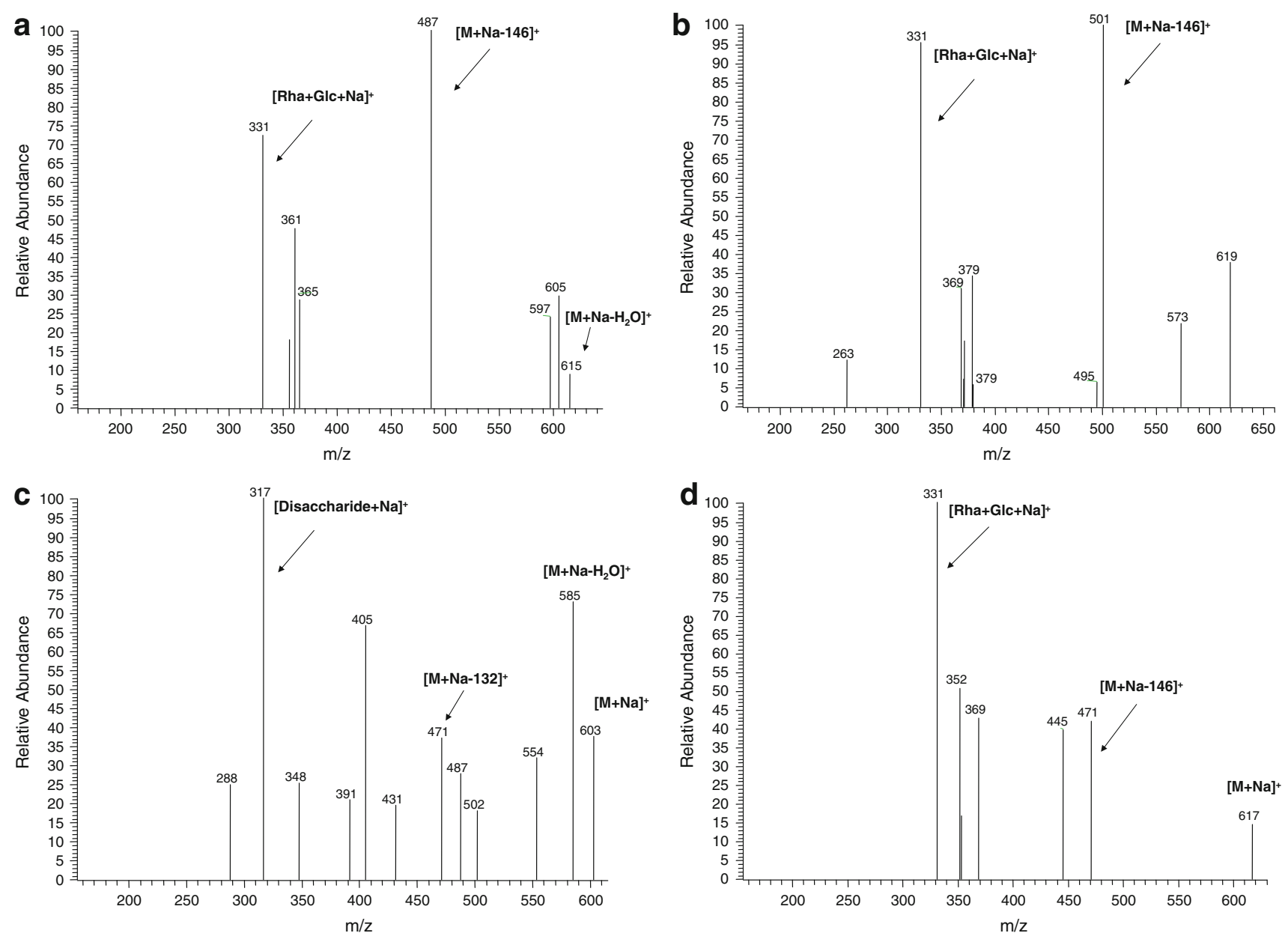

Fig. 6 ESI-MS/MS spectra of ions $[\mathrm{M}+\mathrm{Na}]^{+}$of flavonol glycosides 4 (a), $6(\mathbf{b}), 8$ (c), and 9 (d)
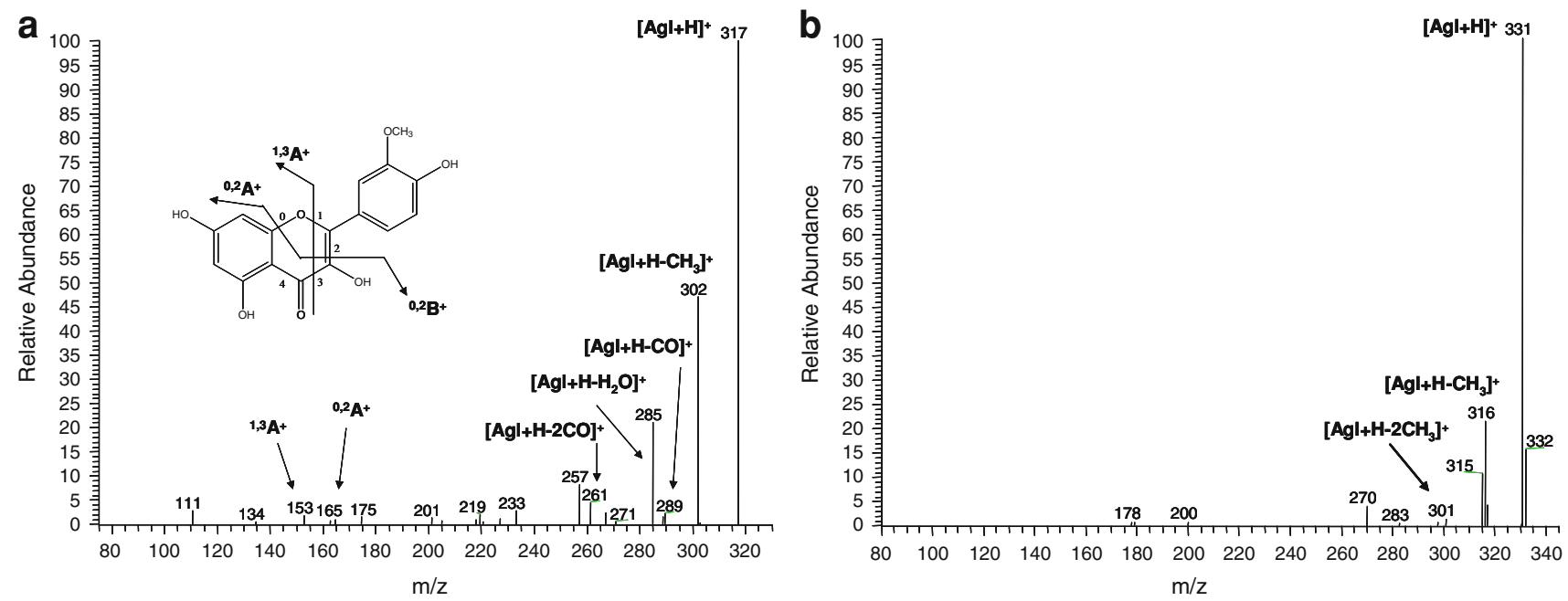

Fig. 7 ESI-MS/MS spectra of ions $[\mathrm{M}+\mathrm{H}]^{+}$of aglyca 10 (a) and $11(\mathbf{b})$

with the $n$-butanol fraction of the fescue plant, suggesting the presence of phytotoxic constituents in this extract. HPLC/PDA-ESI-MS/MS analysis of the active $n$-butanol extract revealed the presence of various classes of secondary metabolites, such as pyrrolizidine alkaloids, flavonol glycosides, and flavonols. Quercetin 3-O-rutinoside, 
isorhamnetin 3-O-rutinoside, and kaempferol 3-O-rutinoside were now reported in fescue for the first time. Previous studies on the allelochemical activity of flavonoids (Buer et al. 2010; Taylor and Grotewold 2005) supported the hypothesis of the allelopathic activity of flavonols detected in fescue.

In allelopathy research, caution must be taken in transferring results from bioassays to field conditions, since evidence for the allelopathic potential of any species may depend either on the choice of the method used to bioassay the activity, or on the choice of the target species (Bertin et al. 2003). Moreover, the presence of allelochemicals in plant tissues may not imply an effective toxic effect in the field, as soil microrganisms may quickly inactivate suppressive allelochemicals. However, in the present investigations, bioassays were not used to demonstrate allelopathic effects caused by fescue, which has already been documented in the literature, but served to guide the isolation of bioactive compounds. Even though results obtained from solvent extractions from plant materials may result in the liberation of chemicals that would not normally be released in the field by living tissue (Lovett and Jessor 1982), such studies have the potential to indicate the allelopathic power, both during the plant life and later during decomposition of plant residues (Inderjit and Weston 2000). Further studies are required in the field to elucidate structures of bioactive constituents in the plant biomass and determine their specific activity and way of action in inhibiting growth of weed seedling.

\section{References}

Belz R, Hurle K (2004) A novel laboratory screening bioassay for crop seedling allelopathy. J Chem Ecol 30:175-198

Bertin C, Paul RN, Duke SO, Weston LA (2003) Laboratory assessment of the allelopathic potential of fine leaf fescues (Festuca rubra L.). J Chem Ecol 8:1919-1937

Buer CS, Imin N, Djordjevic MA (2010) Flavonoids: new roles for old molecules. J Integr Plant Biol 52:98-111

Buta JG, Spaulding DW (1989) Allelochemicals in tall fescueabscisic and phenolic acids. J Chem Ecol 15:1629-1636

Cuyckens F, Claeys M (2004) Mass spectrometry in the structural analysis of flavonoids. J Mass Spectrom 39:1-15

Elakovich SD, Wooten JW (1991) Allelopathic potential of Nuphar lutea (L.) Sibth. \& SM. (Nymphaeaceae). J Chem Ecol 17:707-715

Gilmore AR (1977) How fescue Festuca arundinacea inhibits growth of sweetgum trees Liquidambar styraciflua. Ill Res 19:8-9
Inderjit, Weston LA (2000) Are laboratory bioassays for allelopathy suitable for prediction of field response? $\mathrm{J}$ Chem Ecol 26:2111-2118

Koulman A, Seeliger C, Edwards PJB, Fraser K, Simpson W, Johnson L, Cao M, Rasmussen S, Lane GA (2008) E/Z-thesinine-O-4'$\alpha$-rhamnoside, pyrrolizidine conjugates produced by grasses (Poaceae). Phytochemistry 69:1927-1932

Lovett JV, Jessor RS (1982) Effects of residues of crop plants on germination and early growth of wheat. Aust J Agric Res 33:909-916

Lovett JV, Ryuntyu M (1992) Allelopathy: broadnening the context. In: Rizvi JSH, Rizvi V (eds) Allelopathy: basic and applied aspects. Chapman \& Hall, London, pp 11-18

Ma YL, Li QM, Van den Heuvel H, Claeys M (1997) Characterization of flavone and flavonol aglycones by collision-induced dissociation tandem mass spectrometry. Rapid Commun Mass Spectrom 11:1357-1364

Macias FA, Castellano D, Molinillo JMG (2000) Search for a standard phytotoxic bioassay for allelochemicals. Selection of standard target species. J Agric Food Chem 48:2512-2521

McCalla TM (1971) Studies on phytotoxic substances from microorganisms and crop residues at Lincoln, Nebraska. In: Biochemical interactions among Plants. National Academy of Sciences, Washington DC, pp 39-43

Oyun MB (2006) Allelopathic potentialities of Gliciridia sepium and Acacia auriculiformis on the germination and seedling vigour of maize (Zea mays L.). Am J Agric Biol Sci 1:44-47

Peters EJ, Lun KT (1985) Allelopathy in tall fescue. In: Thompson AC (ed) The chemistry of allelopathy. Symposium Series 268 American Chemical Society, Washington DC, pp 273-283

Rice EL (1984) Allelopathy, 2nd edn. Academic Press, New York

Rizvi SJH, Rizvi V (1992) Allelopathy: basic and applied aspects. Chapman \& Hall, London

Sanchez-Moreiras AM, Weiss OA, Reigosa-Roger MJ (2004) Allelophatic evidence in the Poaceae. Bot Rev 69:300-319

Smith AE, Martin LD (1994) Allelopathic characteristics of three cool-season grass species in the forage ecosystem. Agron $\mathbf{J}$ 86:243-246

Snedecor GW, Cochran WG (1989) Statistical methods, 8th edn. University Press, Iowa State

Springer TL (1996) Allelopathic effects on germination and seedling growth of clovers by endophyte-free and -infected tall fescue. Crop Sci 36:1639-1642

Steel RGD, Torrie JH (1980) Principles and procedures of statistics: a biometrical approach. McGraw-Hill, New York

TA IS (2005) International rules for seed testing. The International Seed Testing Association, Basserdorf

Taylor LP, Grotewold E (2005) Flavonoids as developmental regulators. Curr Opin Plant Biol 8:317-323

Wollenweber E (1982) Flavones and flavonols. In: Harborne JB, Mabry TJ (eds) The flavonoids - advances in researches. Chapman and Hall, London, pp 240-242

Wong E (1980) Flavonol glycosides of tall fescue. NZ J Sci 23:39-42

Zadoks JC, Chang TT, Konzak CF (1974) A decimal code for the growth stages of cereals. Weed Res 14:415-421 